\section{By the Numbers}

\section{Election Data}

\section{Pamela Campbell and Katrina Stierholz}

\section{What's in the Data?}

Election-related information covers a broad range of topicsvoter registration, voter turnout, opinion polls, election results, and campaign finance data-spanning national, state, and local levels. Who collects and provides all the data related to an election? Interestingly, many sources of election statistics are available online through private institutions (e.g., universities, research institutions) rather than government sources. This applies to both recent information and historical information.

This article focuses on just a few of the many resources for election data. Three sources are briefly examined, followed by an in-depth look at one source: the American National Election Studies (ANES). These sources cover a broad range of subject matter and delivery methods. The Library of Congress offers other resources at its election statistics Web Guide (www.loc. gov/rr/program/bib/elections/statistics.html).

\section{Federal Election Commission}

The Federal Election Commission (FEC), an independent regulatory agency established by Congress in 1975, is tasked with enforcing federal campaign finance law, although based on its name, its purview might be perceived as broader than it actually is. The FEC collects and makes available campaign finance data. ${ }^{1}$ The data include detailed receipt and disbursement information for candidates, committees, and political action committees (PACs). Like many data providers, the FEC's methods of providing the data are changing, and application programming interfaces (APIs) are coming into prominence.

Although the scope of the FEC is federal (the president, U.S. Senate, and U.S. House of Representatives), the FEC website does provide contact information for state disclosure offices, as well as brief descriptions of what information may be obtained from each office. ${ }^{2}$

\section{The American Presidency Project}

The nonprofit, nonpartisan American Presidency Project is a collection of presidential election results. ${ }^{3}$ The site provides a color-coded map of the United States-much like the maps the media might use on election night-for each election back to 1789. After the user selects an individual election, data on the

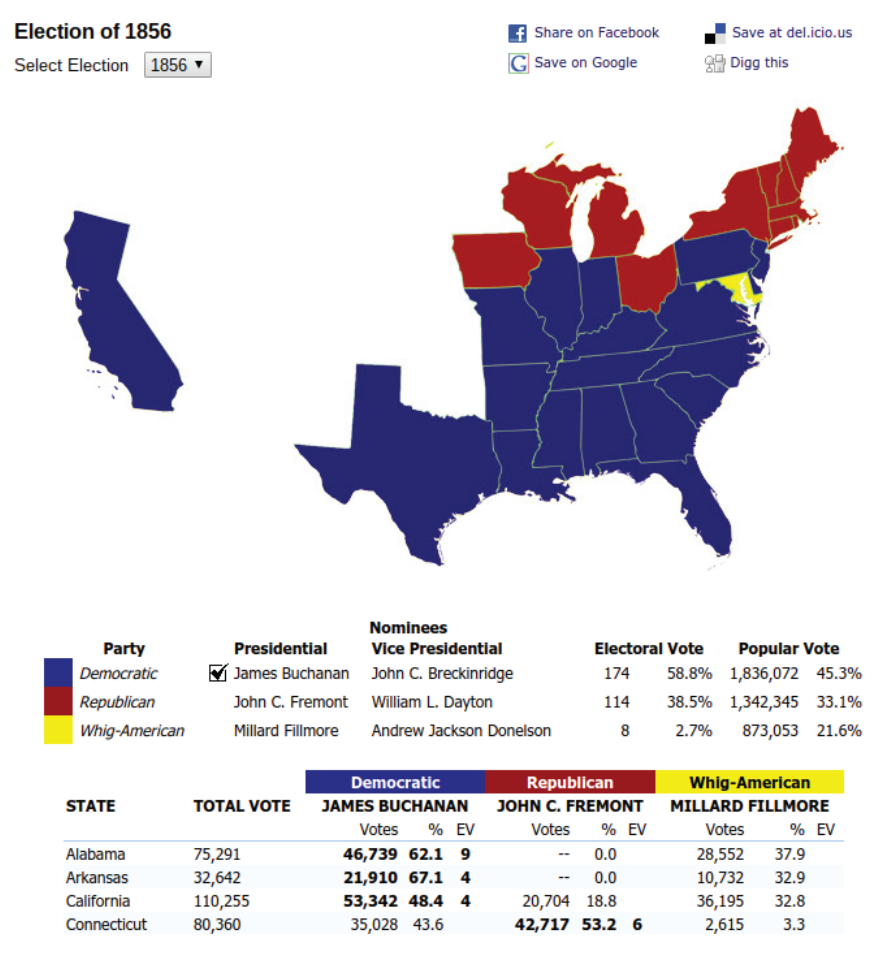

Figure 1. The American Presidency Project. "Election of 1856." www.presidency.ucsb.edu/showelection.php?year $=1856$ captured on July 22, 2016.

electoral vote and popular vote for each state, and the United States as a whole, are shown (figure 1).

The American Presidency Project also provides compiled data, including voter turnout percentages, congressional seats gained or lost by the president's party, and approval ratings, as well as digitized primary sources, such as speeches, executive orders, party platforms, and various other documents. Each dataset is presented in a straightforward table and/or chart; documents (and audiovisual files) are organized intuitively by document type and then by date. No advanced programming or data analysis skills are needed to use this collection.

\section{National Conference of State Legislatures}

The National Conference of State Legislatures (NCSL) is a bipartisan organization dedicated to serving the legislative members and staffs of the nation's states, commonwealths, and territories. In addition to its work to serve these primary constituents, the NCSL hosts several publicly available elections-related legislation databases. These databases, some of which require a free account to access, contain state legislation relating to campaign finance, term limits, and various propositions. ${ }^{4}$

A highlight is the Ballot Measures database, which contains details on statewide initiatives and referendums dating back to 


\section{By the Numbers}

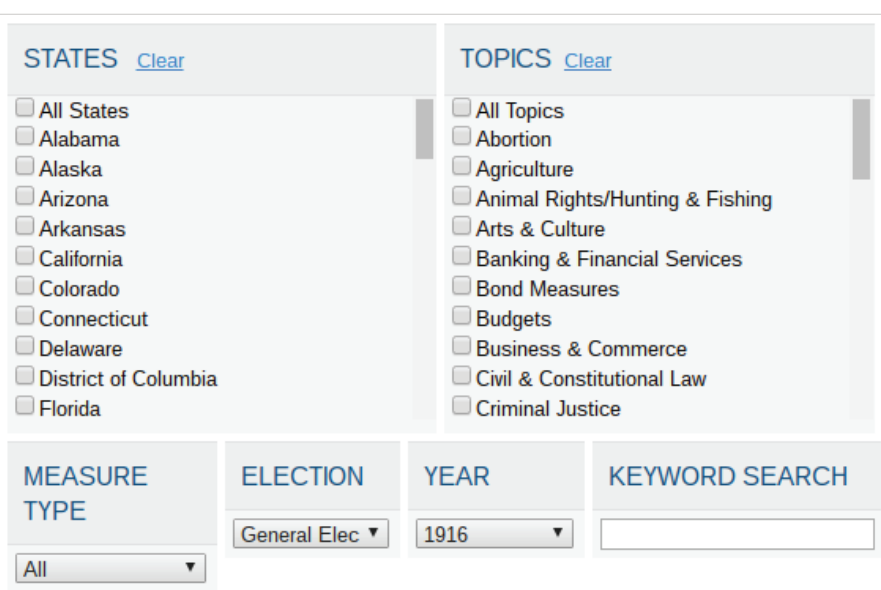

Search

Reset All

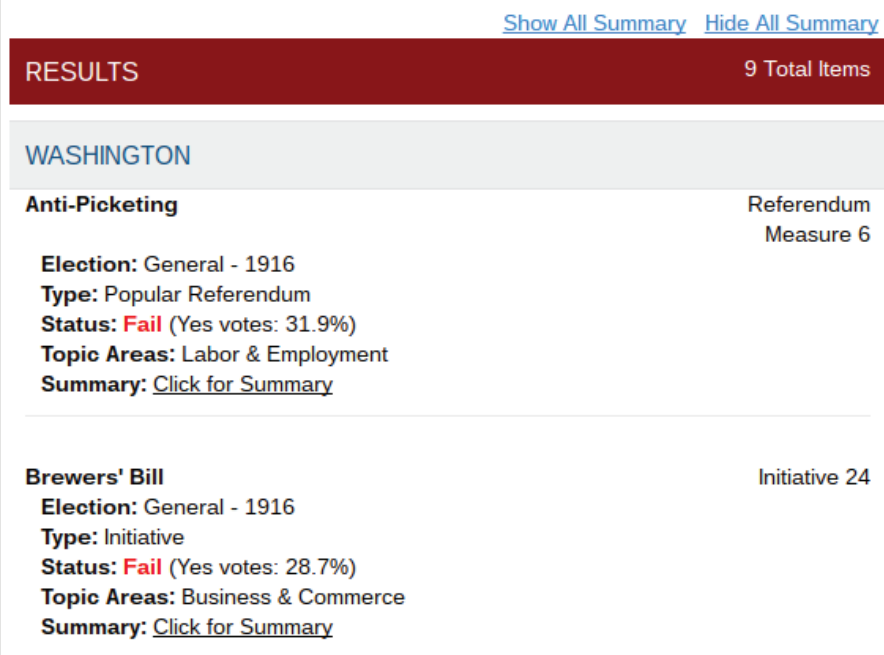

Figure 2. Ballot Measures Database. Source: National Conference of State Legislatures. Ballot Measures Database. www.ncsl.org/research/elections -and-campaigns/ballot-measures-database.aspx captured on July 22, 2016.

\section{SDA (http://sda.berkeley.edu)}

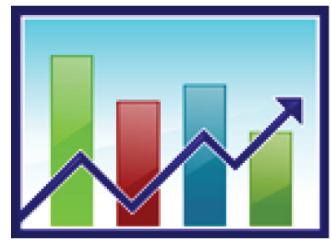

Survey Documentation and Analysis is a handy tool for analyzing the ANES data. Developed at UC Berkeley, it offers a web-based tool for data analysis and is the basis for Interuniversity Consortium for Political and Social Research (ICPSR) instructional materials for ANES.

Figure 3. The SDA tool is useful for analysis of ANES data.

1892. This database's search functionality is intuitive, with filters available by state, topic, measure type, election, year, and keyword. Search results are easy to parse (figure 2).

\section{American National Election Studies}

$\square$ ANES ANES provides an incredible source of election data, voter attitudes, and social changes. The ANES data are useful to know and offer a place to teach data skills (or practice them for yourself).

\section{Background}

ANES is a collaboration of Stanford University and the University of Michigan, with funding from the National Science Foundation. This project began as a product of the University of Michigan's Survey Research Center and the Center for Political Studies of the Institute for Social Research. ANES conducts voter surveys and publishes the survey data. ANES invites the research community to participate in the development of the survey, providing a high-quality data set for students and faculty alike. Visit the main website at electionstudies.org for data and documentation.

\section{Scope}

ANES began in 1948 and has been conducting surveys for nearly every presidential and congressional election since then. ${ }^{6}$ In addition, special studies and pilot studies provide additional information on the opinions of the American electorate. The surveys have a high response rate, are conducted face-to-face, and offer a deep understanding of public opinions and political attitudes. Beginning in 2012, the survey data were supplemented with data collection on the Internet. Participating typically consists of an hour-long interview conducted between Labor Day and Election Day, followed by repeat interviews of the same participants in their homes after Election Day until mid-December. While ANES researchers strive to have consistent questions to allow for a long time series, this study is also regularly updated and enhanced to capture current issues and events. Researchers describe the ANES as the gold standard for social survey research. ${ }^{7}$

\section{Uses}

The ANES is a tremendous data set for scholars and their research. The survey is sufficiently broad in scope that it is used by many researchers in the social sciences, not just political science. The data are available for download and use in standard statistical analysis software packages, and all documentation is online. The data set is extremely well documented, accessible, and valuable for researchers. The data are also available through the Survey Documentation and Analysis (SDA) interface, a webbased tool for analysis of survey data available at sda.berkeley.edu /archive.htm (figure 3). Providing referrals to ANES is an important part of a data librarian's work for researchers. 


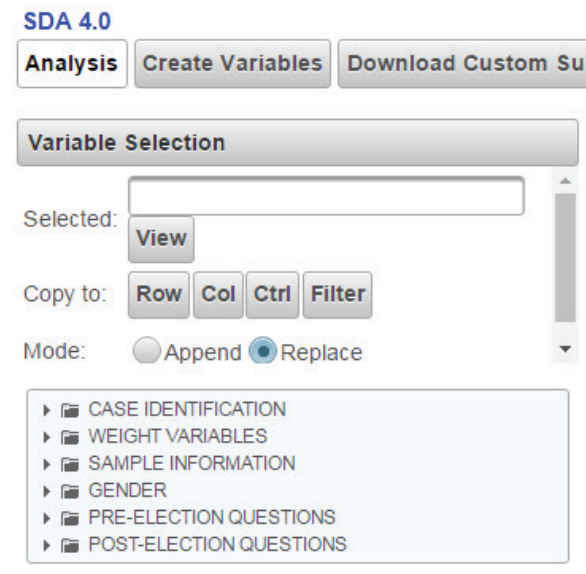

Selected Study: ANES 2012 Time Series

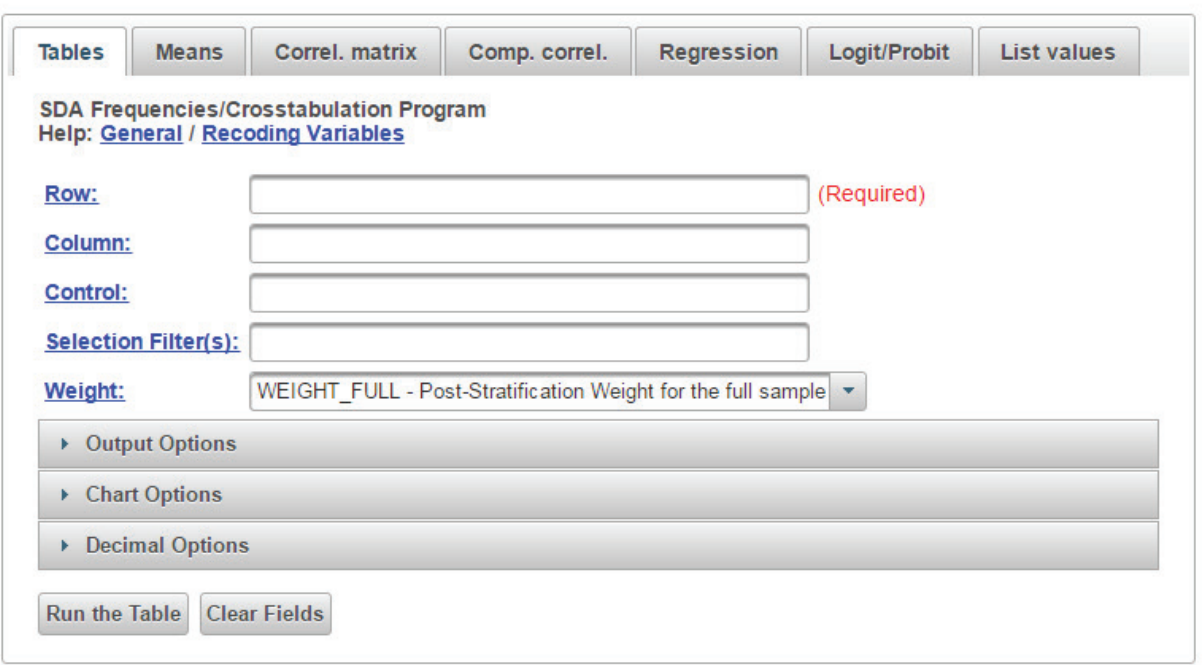

Figure 4. SDA tool for ANES 2012. ANES 2012 page at SDA, sda.berkeley.edu/sdaweb/analysis/?dataset=nes2012. Source: SDA: Survey Documentation and Analysis website, at the University of California, Berkeley, ANES 2012 Time Series Study Analysis.

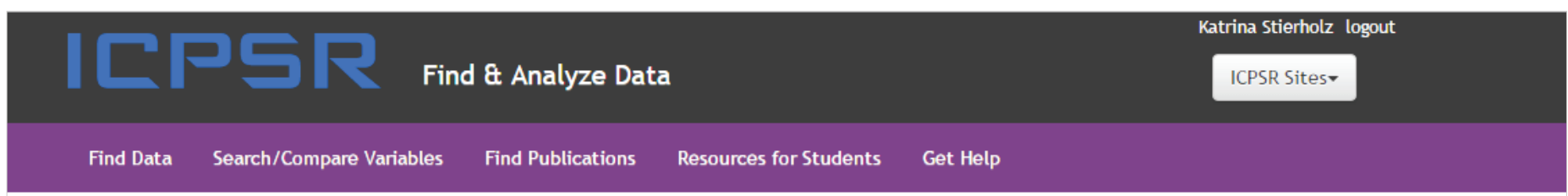

Select Variables

Type the name of the variable in the row, column, control, or selection filter box.

Click on the variable for more information about it.

$\nabla$ ADMINISTRATIVE

VARIABLES

$\nabla$ VOTING BEHAMOR AND RELATED ITEMS

$\checkmark$ POLITICAL

INVOLVEMENT AND

PARTICIPATION ITEMS

$\checkmark$ MEDIA EXPOSURE

AND CONSUMPTION

ITEMS

$\checkmark$ CANDIDATE IMAGE

ITEMS

$\nabla$ PRESIDENTIAL AND

CONGRESSIONAL

PERFORMANCE ITEMS

$\nabla$ ECONOMIC

CONDITIONS ITEMS

$\checkmark$ IDEOLOGY ITEMS

$\checkmark$ TAXATION AND

BUDGET ITEMS

$\checkmark$ ECONOMIC AND

SOCIAL WELFARE ITEMS

$\checkmark$ SOCIAL AND MORAL

ISSUE ITEMS

\begin{abstract}
study: SETUPS: Voting Behavior: The 2012 Election > Select Variables
\end{abstract}

\section{SETUPS: Voting Behavior: The 2012 Election}

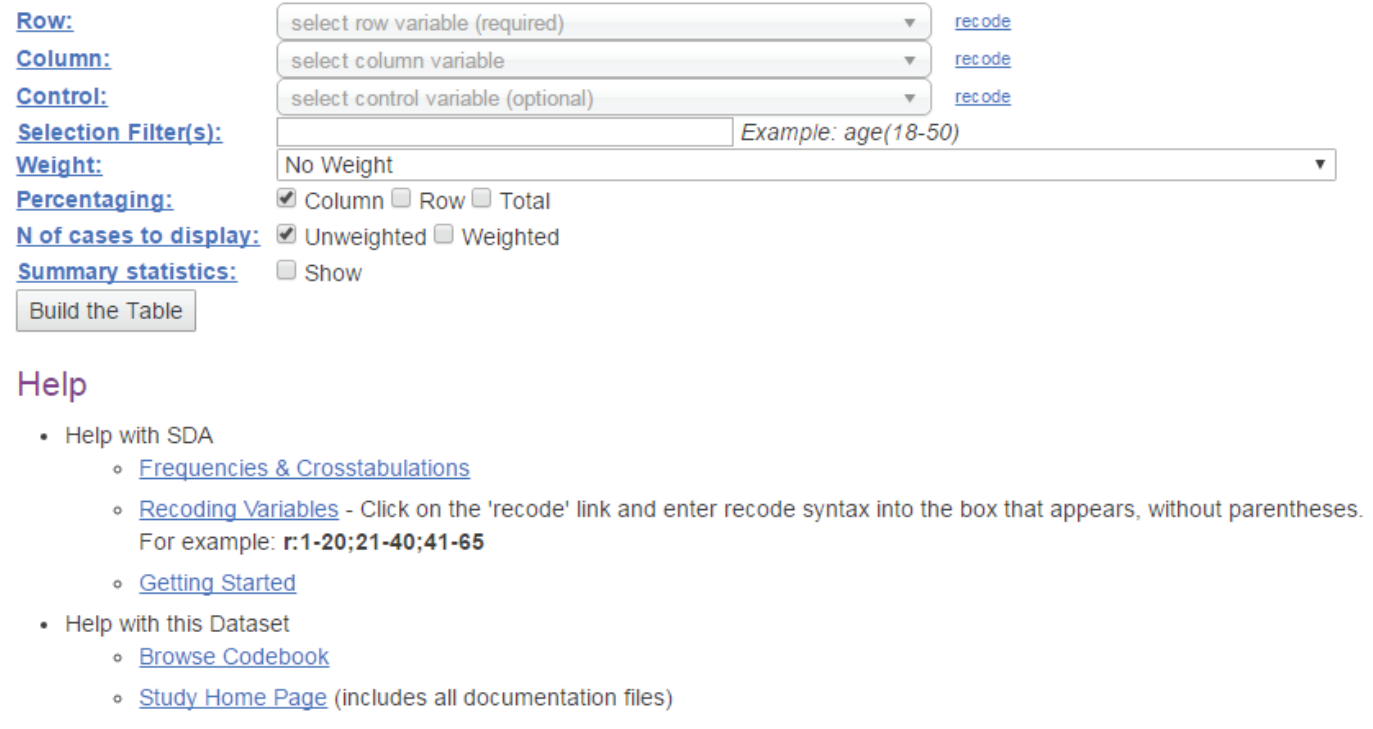

Figure 5. SETUPS version of SDA (note the pull-down menus to select variables). Supplementary Empirical Teaching Units in Political Science (SETUPS) is offered at the ICSPR website, www.icpsr.umich.edu/icpsrweb/ICPSR/studies/34808/datasets/0001/sdaxml. Source: Inter-university Consortium for Political and Social Research, Institute for Social Research, University of Michigan. 


\section{By the Numbers}

\section{Library Instruction}

For librarians giving students an overview of a data set, ANES offers an interesting opportunity-the ANES and ICSPR have regularly produced a subset of the ANES data to use with students, creating lessons for students to analyze the data. This subset, SETUPS (Supplementary Empirical Teaching Units in Political Science), is offered on the ICSPR website at under the title "Voting Behavior: The 2012 Election" and offers a complete set of instructional resources for the ANES data (www .icpsr.umich.edu/icpsrweb/instructors/setups2012/index.jsp). The data are a subset of the 2012 data capture and provide stepby-step exercises to provide students the opportunity to analyze data from the 2012 election. The site offers background information on already-known voter behavior (considerations for candidate selection and attitudinal factors), a codebook for the SETUPS data set (smaller and simpler than the codebook for the overall data), an explanation of the sampling techniques used in the ANES data, sources of error in surveys, and an explanation of variables. The links on the left side of the page are sequential and should be used sequentially to help prepare yourself and students for the analysis exercises.

Students need to create an account with ICPSR, but there is no cost. The SETUPS tool uses the SDA program and provides additional support for new users. The presentation of the data is similar to that in the original SDA but with more scaffolding. Users use pull-down menus to select variables (rather than using a codebook to locate the variable and then entering it), and checkboxes are used to make changes to the analysis. The data exercises start small and simple (a two-variable relationship on party identification and the presidential vote). They move to recoding data for better presentation, then to three variables, and so on. Each exercise also has questions to consider when reading and interpreting the data. The sequential steps suggest this data set as an excellent resource for library instruction in using data (see figures 4 and 5).

ANES provides an invaluable tool for researchers and librarians, as well as teachers and students. It offers high value for researchers already comfortable with using data, but it is also a tool with instructions to assist students and others new to analyzing data. With the upcoming election, the topic is pressing and student interest will be high. This could be a great time to add ANES to your teaching toolkit.
Pamela Campbell (pamela.d.campbell@stls.frb.org) is Senior Librarian, Federal Reserve Bank of St. Louis. Katrina Stierholz (katrina.l.stierholz@stls.frb.org) is Vice President and Director of Library and Research Information Services.

\section{References}

1. Federal Election Commission, "About the FEC," access August 8, 2016, www.fec.gov/about.shtml.

2. Federal Election Commission, "Combined Federal/State Disclosure and Election Directory 2016," accessed August 8, 2016, www.fec.gov/pubrec/cfsdd/cfsdd.shtml.

3. The American Presidency Project, hosted at the University of California, Santa Barbara, has been a collaboration between John T. Woolley (UCSB) and Gerhard Peters (Citrus College). The American Presidency Project, accessed August 8, 2016, www.presidency.ucsb.edu/ index.php.

4. Wendy Underhill, "Elections-Related Legislation Databases," March 23, 2015, www.ncsl.org/research/elections -and-campaigns/elections-legislation-databases-descrip tion.aspx.

5. National Conference of State Legislatures, "Ballot Measures Database," accessed August 8, 2016, www.ncsl.org/ research/elections-and-campaigns/ballot-measures-data base.aspx.

6. American National Election Studies, "ANES TimeSeries: Sample and Mode by Wave," August 29, 2016, www.electionstudies.org/helpcenter/TimeSeriesByWave .pdf.

7. John H. Aldrich and Kathleen M. McGraw, "Introduction to the Volume," in Improving Public Opinion Surveys: Interdisciplinary Innovation and the American National Election Studies, edited by John H. Aldrich and Kathleen M. McGraw (Princeton, NJ: Princeton University Press, 2012), 4-8. 